\title{
Difusão de organismos geneticamente modificados e seus aspectos contraditórios
}

\section{Evânio do Nascimento Felippe}

Segundo Goldin e Resende (1993), o desenvolvimento da agricultura pode ser apresentado por meio de uma seqüência de três estágios. No primeiro, ocorrido há cerca de 10 mil anos, o homem utilizou práticas e técnicas (rudimentares) que o possibilitou cultivar plantas de modo a garantir sua provisão e, consequentemente, sua sobrevivência. O segundo estágio ocorrido por volta dos anos de 1960 e denominado de 'revolução verde' é caracterizado pelo emprego da tecnologia na agricultura. Nesta fase, o desenvolvimento tecnológico consistiu no uso intensivo de herbicidas e fertilizantes e maior mecanização das atividades agrícolas que proporcionaram uma rápida expansão na produção de alimentos. $\mathrm{O}$ último estágio, marcado pelo emprego da biotecnologia no setor agrícola, consiste não apenas na busca de aumentos na produtividade da produção agrícola como também avanços qualitativos na produção de alimentos tornando-os mais 'saudáveis' e 'seguros'.

A partir da "revolução verde", a agricultura contemporânea tem apresentado aumentos significativos na quantidade e na qualidade de sua produção.

Tabela 1. Produção agrícola mundial (mil/ton.)

\begin{tabular}{cccccc}
\hline Ano & Arroz & Algodão & Milho & Soja & Trigo \\
\hline 1961 & 215.655 & 27.344 & 205.005 & 26.883 & 222.357 \\
1970 & 316.384 & 35.444 & 265.831 & 43.697 & 310.742 \\
1980 & 396.871 & 41.214 & 396.623 & 81.040 & 440.204 \\
1990 & 518.229 & 54.308 & 483.336 & 108.453 & 592.309 \\
2000 & 599.098 & 53.058 & 592.790 & 161.406 & 586.060 \\
2005 & 618.441 & 68.298 & 701.666 & 214.347 & 629.566 \\
\hline
\end{tabular}

Fonte: FAO (http://www.fao.org)

De acordo com a tabela 1, o arroz, o milho e a soja, por exemplo, têm apresentado, respectivamente, um crescimento de 186,8\%,242,3\% e 697,3\% no período de 1961 a 2005. Fator marcante que tem favorecido esse desempenho é a crescente aplicação dos meios tecnológicos para os mais diversos fins como, por exemplo, a utilização da biotecnologia para a prática agrícola. Dentre as amplas possibilidades de uso da biotecnologia, está o

\footnotetext{
* Mestrando em Desenvolvimento Econômico pela Universidade Federal do Paraná (UFPR) e bolsista pelo CNPq. Endereço eletrônico: efelippe@yahoo.com.br
} 
desenvolvimento e melhoramento das sementes aplicadas na agricultura, ou seja, a manipulação genética do grão com o intuito de alcançar maior produtividade e qualidade do produto. Conhecida como organismos geneticamente modificados (OGMs), ou transgênicos, essa técnica consiste em inserir genes estranhos na estrutura genética do grão. A inserção de genes ocorre por meio de transferência de um ou mais genes responsáveis por uma determinada característica de um organismo para outro organismo, ao qual se pretende incorporar esta característica. Essa nova técnica de plantio tem conquistado espaço entre os mais diversos produtores de todo o mundo nos últimos 10 anos, apresentando um crescimento acelerado, ano após ano, em termos de área destinada ao cultivo de plantas transgênicas. No entanto, as externalidades provocadas por essa nova técnica de plantio ainda estão revestidas de aspectos contraditórios no que se refere a sua produtividade e segurança para a saúde humana e ao meio ambiente se comparado aos alimentos produzidos convencionalmente.

Sendo assim, o objetivo deste artigo é analisar o processo de difusão de organismos geneticamente modificados na agricultura. Nesse sentido busca-se identificar as principais culturas e os principais países que tem adotado e utilizado a nova técnica de produção. Além disso, analisam-se os aspectos contraditórios da utilização dessa nova tecnologia, buscando analisar o ambiente ainda incerto quanto à segurança do uso de alimentos geneticamente modificados para a alimentação e ao meio ambiente (redução no uso de herbicidas). Analisam-se também os seus possíveis impactos na redução de custos de produção e no aumento de sua produtividade.

\section{A produção de organismos geneticamente modificados (OGMs) em 2005}

Num relatório divulgado pela International for the Acquisition of Agri-Biotech Aplication (ISAAA) foi apresentado a situação global da produção de organismos geneticamente modificados nos últimos dez anos, mostrando o valor global deste novo mercado e também a área destinada ao cultivo de plantas transgênicas.

Segundo estimativas apresentadas neste relatório, o valor global do mercado de organismos geneticamente modificados em 2005, foi de US\$ 5,25 bilhões. Para se ter uma idéia, essa cifra representou $18 \%$ dos US $\$ 30$ bilhões do mercado de sementes no ano de 2005. Os principais produtos deste mercado, por ordem de importância, são: soja (46\%), milho (36\%), algodão (14\%) e canola (4\%). Nos últimos 10 anos, as estimativas do valor 
global acumulado do mercado de OGMs estão em torno de US\$29,3 bilhões e as projeções para o ano de 2006 apresentam cifras superiores a US\$ 5,5 bilhões.

Ainda de acordo com este estudo, no período de 1996 a 2005, a área total destinada ao cultivo de plantas transgênicas chegou a 475 milhões de hectares. Em 2005 foram destinados mais de 90 milhões de hectares para o cultivo de plantas transgênicas em 21 países.

Tabela 2. Área global de lavouras OGMs em 2005 (milhões de hectares)

\begin{tabular}{cccc}
\hline Posição & País & Área & Lavouras GM \\
\hline $1^{*}$ & EUA & 49,8 & Soja, milho, algodão, canola, abóbora, papaia \\
$2^{*}$ & Argentina & 17,1 & Soja, milho, algodão \\
$3^{*}$ & Brasil & 9,4 & Soja \\
$4^{*}$ & Canadá & 5,8 & Canola, milho, soja \\
$5^{*}$ & China & 3,3 & Algodão \\
$6^{*}$ & Paraguai & 1,8 & Soja \\
$7^{*}$ & Índia & 1,3 & Algodão \\
$8^{*}$ & África do Sul & 0,5 & Milho, soja, algodão \\
$9^{*}$ & Uruguai & 0,3 & Soja, milho \\
$10^{*}$ & Austrália & 0,3 & Algodão \\
$11^{*}$ & México & 0,1 & Algodão, soja \\
$12^{*}$ & Romênia & 0,1 & Soja \\
$13^{*}$ & Filipinas & 0,1 & Milho \\
$14 *$ & Espanha & 0,1 & Milho \\
15 & Colômbia & $<0,1$ & Algodão \\
16 & Irã & $<0,1$ & Arroz \\
17 & Honduras & $<0,1$ & Milho \\
18 & Portugal & $<0,1$ & Milho \\
19 & Alemanha & $<0,1$ & Milho \\
20 & França & $<0,1$ & Milho \\
21 & República Tcheca & $<0,1$ & Milho \\
\hline & & &
\end{tabular}

Fonte: Clive James, 2005.

Nota: * 14 mega-países produzindo 50 mil hectares ou mais de lavouras GM. Todos os dados em hectares foram arredondados na casa de 100 mil hectares e em alguns casos, isto significa um grau insignificante de variância. Descrições mais detalhadas sobre a situação das lavouras GM em cada país serão dadas na versão completa do relatório 34 .

Através da tabela 2, observa-se que os EUA é o principal país a utilizar essa nova tecnologia na agricultura. Pelos dados apresentados, aquele país destina 49,8 milhões de hectares, ou seja, praticamente a metade de sua área, para o plantio de produtos OGMs. Na 
Argentina e no Brasil, outros principais players do mercado de alimentos, as áreas totais ocupadas pelas lavouras transgênicas em 2005 foram, respectivamente, de 17,1 e 9,4 milhões de hectares. Segundo relatório do ISAAA, dos principais países produtores mundiais de alimento, o Brasil foi o país que apresentou o maior aumento na área destinada ao cultivo de OGMs. Passou de 5,0 milhões de hectares em 2004 para 9,4 milhões em 2005, um aumento de $88 \%$ na área destinada ao cultivo de plantas transgênicas.

O estudo ainda revela que a soja geneticamente modificada é a principal lavoura a ocupar as áreas destinadas ao cultivo de OGMs. Em 2005, o cultivo da soja geneticamente modificada ocupou uma área de 54,4 milhões de hectares ou $60 \%$ da área total. Outros produtos, como o milho com $24 \%$ de ocupação, algodão (11\%) e canola (5\%) são, respectivamente, outras principais lavouras a ocupar a área total destinado ao cultivo de plantas transgênicas.

Outro resultado que o relatório apontou é a crescente adoção por parte dos países em desenvolvimento da nova técnica de produção baseada no cultivo de plantas transgênicas. Dos 21 países que cultivaram lavouras geneticamente modificadas em 2005, 11 eram países em desenvolvimento e 10 eram países industrializados.

Mapa 1. Área global de lavouras geneticamente modificadas

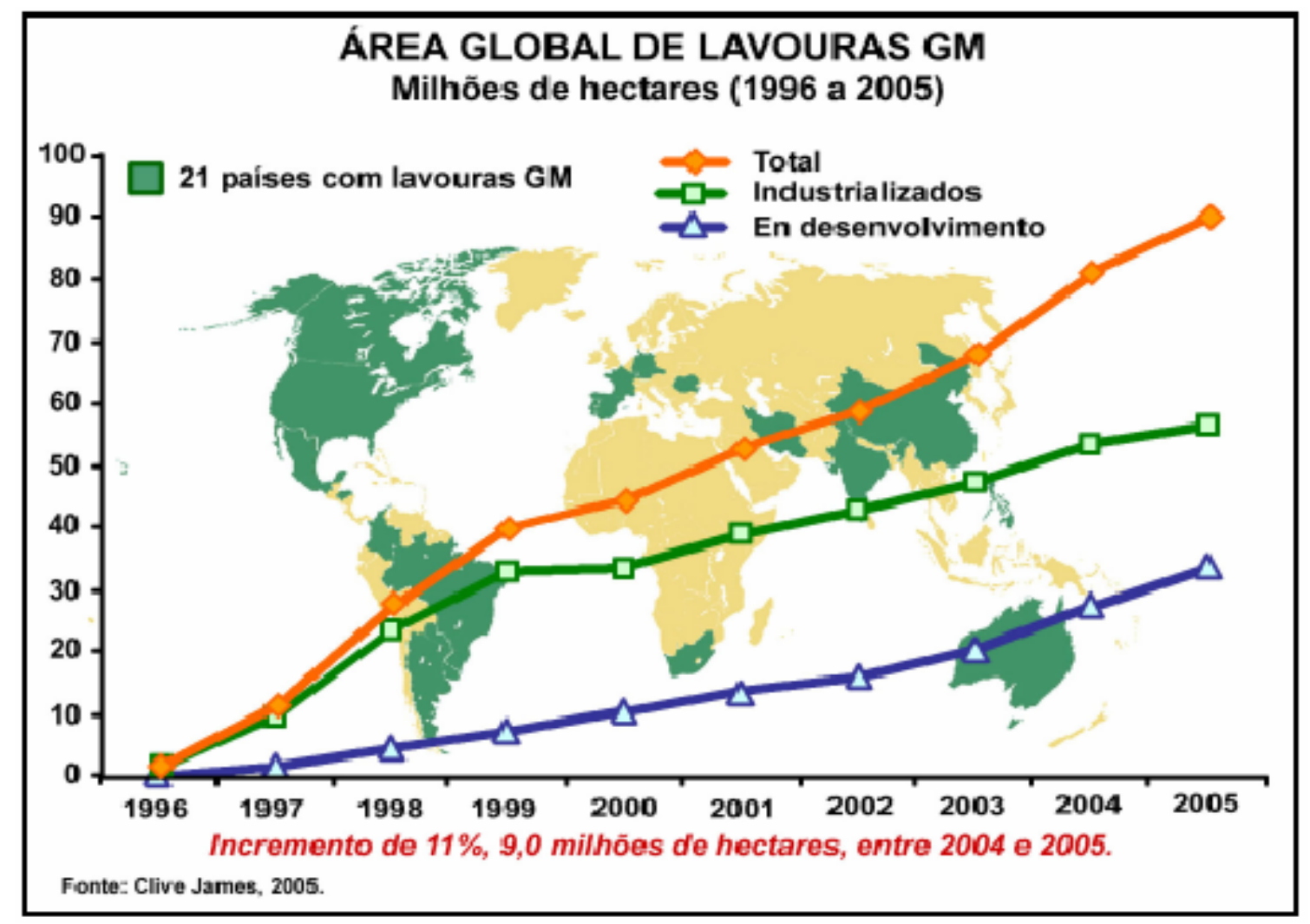

Fonte: ISAAA

84 
Pelo estudo apresentado, conforme o mapa 1, os países em desenvolvimento têm aumentado suas áreas destinadas ao cultivos de OGMs ano após ano. Segundo relatório divulgado pelo ISAAA, em 2005, mais de $1 / 3$ da área semeada com plantas transgênicas foram cultivados em países em desenvolvimento. A taxa de crescimento nesses países, 27\% no período 2004 e 2005, foi muito superior ao dos países em desenvolvimento, 5\% no mesmo período. Esses dados podem indicar uma importante e contínua tendência para a adoção e aceitação em escala mundial ainda maior das lavouras geneticamente modificadas.

\section{Aspectos contraditórios}

Os aspectos contraditórios apresentados pela nova tecnologia de plantio (transgênica) frente à tecnologia de cultivo baseada na utilização de sementes convencionais, referem-se as suas externalidades. Ainda não há estudos conclusivos que evidenciem de forma categórica que uma tecnologia é superior à outra em termos de produtividade e de redução nos custos de produção. Além disso, a nova tecnologia carrega consigo aspectos incertos sobre os seus reais impactos sobre a saúde humana e ao meio ambiente. As discussões que tem permeado este debate apresentam duas posições antagônicas. De um lado, há um grupo da comunidade científica que defende o uso da biotecnologia como provedora de soluções capazes de reduzir a fome e aumentar a qualidade dos alimentos. De outro, há um grupo que questiona o uso desta tecnologia por causar impacto sobre a saúde e ao ambiente.

\subsection{OGMs: riscos à saúde humana e ao meio ambiente?}

Esta parte do trabalho consiste em apresentar os argumentos positivos e negativos ligados à produção e consumo de alimentos transgênicos. Procura-se evidenciar os aspectos ainda contraditórios entre as duas correntes da comunidade científica que defendem o uso de alimentos transgênicos.

Aquele grupo que defende o uso de transgênicos apresenta alguns aspectos positivos de seu consumo em seu argumento. Esses aspectos são: os alimentos transgênicos são mais resistentes a pragas e herbicidas; são mais resistentes a doenças causadas por vírus, bactérias e fungos; possui característica de florescimento rápido; possui maior tolerância a pressões abióticas (salinidade). Além desses aspectos, outros aspectos positivos que as plantas transgênicas apresentam são: a maior flexibilidade no manejo das plantações, a redução na dependência de inseticidas químicos; e a possibilidade do uso de plantas transgênicas para a produção de vacinas contras doenças humanas e de animais. 
Por outro lado, há correntes que divergem desses benefícios. De acordo com Nodari e Guerra (2003), os riscos pelo uso de plantas transgênicas podem ser classificados em dois grupos: alergênicos e intolerantes. No caso de alimentos alergênicos, esses causam a hipersensibilidade alérgica. O segundo grupo refere-se a alterações fisiológicas como reações metabólicas anormais e toxicidade. Além do mais, essa corrente argumenta que o uso de transgênicos para a alimentação pode gerar riscos a saúde humana por meio de reações alérgicas que podem ocorrer no consumo deste produto. $\mathrm{O}$ uso de transgênicos ainda pode causar: aumento na contaminação do solo e do lençol freático devido ao uso intensivo de agrotóxico; gerar o surgimento e/ou desenvolvimento de plantas e animais resistentes a agrotóxicos; ameaçar as plantas silvestres e as variedades nativas reduzindo assim a biodiversidade; aumentar a ocorrência de poluição genética e surgimento de 'superpragas'; gerar o extermínio de insetos benéficos para a agricultura, etc.

Como pode se observar, os riscos da utilização de culturas geneticamente modificadas para a saúde humana e ao meio ambiente ainda carecem de estudos conclusivos sobre os seus reais impactos. O que se tem atualmente são argumentos que procuram defender a adoção ou não de uma nova tecnologia para sua utilização na agricultura. Dado que não há estudos conclusivos de modo a evidenciar as externalidades positivas das culturas geneticamente modificadas, alguns pesquisadores propõem a utilização do princípio da precaução para a produção e a comercialização destes tipos de produtos.

\subsection{Tecnologia transgênica versus tecnologia convencional}

O uso da tecnologia transgênica é superior à tecnologia convencional, no que se refere aos custos de produção, uso de agrotóxicos e produtividade? Tentando responder esta questão, abordaremos o tema procurando comparar os custos de produção ${ }^{13}$, a quantidade de herbicidas utilizados e a produtividade que cada técnica apresenta. Por se tratar da principal cultura que utiliza a tecnologia transgênica, o produto analisado será a soja. E os países estudados que adotam a tecnologia transgênica serão os Estados Unidos e Argentina. Dada a indisponibilidade de informações e a liberalização do plantio e comercialização de soja transgênica a partir de 2006, o Brasil, outro principal país produtor de soja, fará parte da análise apenas na comparação do item produtividade.

\footnotetext{
${ }^{13}$ Dada às diferenças das estruturas de custos e os fatores que afetam a produtividade, as comparações de custos entre os cultivos de transgênicos e convencionais, segundo BENBROOK (2001), devem ser realizadas em uma mesma região, no mesmo intervalo de tempo e para um mesmo sistema de plantio (direto ou tradicional)
} 


\section{Custos de produção}

Pelas tabelas abaixo, os custos de produção da soja nos EUA (estudo realizado nos Estado de Wisconsin) e Argentina apresentaram os seguintes resultados ${ }^{14}$.

Tabela 3. Custos de produção de soja nos EUA em 1999 (US\$/ha)

\begin{tabular}{lcccc}
\hline \multirow{2}{*}{ Item } & \multicolumn{2}{c}{ Plantio tradicional } & \multicolumn{2}{c}{ Plantio direto } \\
\cline { 2 - 3 } \cline { 5 - 5 } & Roundup Ready & Convencional & Roundup Ready & Convencional \\
\hline Sementes & 74,5 & 55,35 & 83,4 & 62,47 \\
Controle de ervas daninhas & & & & \\
- Roundup (1.5 pt pré) & & & 19,15 & 19,15 \\
- Raptor & & 60,79 & & 60,79 \\
- Adjuvantes & & 3,71 & & 3,71 \\
- Roundup (1.5 pt) & 19,15 & & 19,15 & \\
Custo de aplicação & 17,3 & 17,3 & 34,59 & 34,59 \\
Custo total & $\mathbf{1 1 0 , 9 5}$ & $\mathbf{1 3 7 , 1 4}$ & $\mathbf{1 5 6 , 2 9}$ & $\mathbf{1 8 0 , 7}$ \\
\hline
\end{tabular}

Fonte: Rankin (1999).

Tabela 4. Custos de produção de soja na Argentina, 2001 (US\$/ha)

\begin{tabular}{lccccc}
\hline \multirow{2}{*}{ Item } & \multicolumn{2}{c}{ Variedade convencional } & & \multicolumn{2}{c}{ Variedade RR } \\
\cline { 5 - 6 } Custos Variáveis & Média & Desvio & & Média & Desvio \\
\hline Sementes & 17,19 & 6,48 & 20,8 & 9,74 \\
Herbicidas & 33,64 & 16,55 & 19,1 & 5,7 \\
Outros químicos & 13,55 & 8,85 & 13,82 & 8,68 \\
Máquinas & 24,25 & 18,65 & 17,43 & 15,78 \\
Salários e custos de produção & 46,82 & 25,4 & 43,22 & 23,27 \\
Comercialização & 77,54 & 20,87 & 77,91 & 19,66 \\
Custos variáveis totais & $\mathbf{2 1 2 , 9 9}$ & $\mathbf{2 9 , 7 1}$ & $\mathbf{1 9 2 , 2 9}$ & $\mathbf{2 6 , 4 7}$ \\
Custo de produção unitário (US\$/t) & $\mathbf{7 3 , 3 6}$ & $\mathbf{1 5 , 7 7}$ & $\mathbf{6 5 , 7 9}$ & $\mathbf{1 2 , 1 3}$ \\
\hline
\end{tabular}

Fonte: Qaim \& Traxler (2002).

As informações mostram que, tanto nos EUA quanto na Argentina, os custos de produção com a variedade de soja que utilizam o Roundup Ready (RR) foram menores. Nos EUA, o custo de controle com ervas daninhas da produção da soja RR, no cultivo tradicional, foi $19 \%$ inferior à produção do cultivo de soja convencional. O mesmo resultado observa-se

\footnotetext{
${ }^{14}$ Os resultados deste trabalho encontram-se também em In: PELAEZ, V; ALBERGONI, L; GUERRA, M., Cadernos de Ciência \& Tecnologia, Brasília, v. 21, n.2, p. 279-309, maio/ago. 2004
} 
para o cultivo direto só que com uma margem menor 13,5\%. Na Argentina, tabela 4, os custos de produção da soja RR em comparação com a soja convencional também apresentaram resultados parecidos ao da agricultura norte-americana. O custo do cultivo de soja transgênica na Argentina foi 10,3\% inferior ao custo do cultivo de soja convencional.

De acordo com essas informações, o custo de cultivo da soja transgênica mostra-se inferior aos custos de cultivo da soja convencional.

\section{Uso de agrotóxicos}

No que se refere à quantidade utilizada de agrotóxicos, a tecnologia transgênica é vendida com a promessa de redução no uso de herbicidas (glifosato), o que significa uma diminuição dos custos de produção e preservação do meio ambiente. No entanto, alguns dados mostram o contrário. Estudos realizados na Argentina por Qaim \& Traxler, mostraram um aumento de $108 \%$ na quantidade total de herbicidas (dentre eles o glifosato) utilizados no cultivo da soja RR.

Tabela 5. Quantidade de herbicidas utilizadas no cultivo de soja (Argentina, 2001)

\begin{tabular}{lrrr}
\hline \multicolumn{1}{c}{ Tipos de herbicidas } & Convencional (1/ha) & RR (1/ha) & Variação (\%) \\
\hline Herbicidade de toxicidade classe II & 0,42 & 0,07 & $-83,3$ \\
Herbicidade de toxicidade classe III & 0,68 & 0 & -100 \\
Herbicidade de toxicidade classe IV & 1,58 & 5,5 & 248,1 \\
Quantidade total de herbicidas & 2,68 & 5,57 & 107,8 \\
\hline
\end{tabular}

Fonte: Qaim \& Traxler. In: PELAEZ V. et all. (2004).

Estes autores mostram que houve uma redução, de acordo com a classificação internacional da organização mundial de saúde, de herbicidas mais tóxicos (classes II e III). No entanto, essa redução é contrabalançada pelo aumento do uso de herbicidas da classe IV, menos tóxica, ao qual pertence o herbicida glifosato. Outro estudo realizado por Benbrook (2001) nos EUA, mostra um aumento médio no consumo do herbicida glifosato por parte dos Estados produtores de soja OGM. 
Tabela 6. Quantidade de herbicidas utilizados em estados dos EUA, 1998

\begin{tabular}{|c|c|c|c|}
\hline \multirow{2}{*}{ Estado } & \multicolumn{3}{|c|}{ Total de herbicidas (kg/ha) } \\
\hline & $\overline{\mathbf{R R}}$ & Convencional & RR/Convencional \\
\hline$\overline{\text { Arkansas }}$ & 1,68 & 1,03 & 1,63 \\
\hline Dakota do Sul & 1,59 & 1,08 & 1,47 \\
\hline Minnesota & 1,29 & 0,94 & 1,37 \\
\hline Tenesse & 2 & 1,54 & 1,30 \\
\hline Iowa & 1,57 & 1,21 & 1,30 \\
\hline Indiana & 1,19 & 1,04 & 1,14 \\
\hline Ohio & 1,31 & 1,17 & 1,12 \\
\hline Mississipi & 1,59 & 1,55 & 1,03 \\
\hline Kentucky & 1,26 & 1,22 & 1,03 \\
\hline Louisiana & 0,51 & 1,5 & 0,34 \\
\hline Illinois & 1,22 & 1,29 & 0,95 \\
\hline Kansas & 0,95 & 1,03 & 0,92 \\
\hline Missouri & 1,38 & 1,5 & 0,92 \\
\hline Carolina do Norte & 1,28 & 1,46 & 0,88 \\
\hline Nebraska & 1,39 & 1,63 & 0,85 \\
\hline Michigan & 1,15 & 1,65 & 0,70 \\
\hline Média & 1,37 & 1,21 & 1,13 \\
\hline
\end{tabular}

Fonte: Benbrook (2001); USDA (1999) e Vegetable Summary. In: In: PELAEZ, V et al., Cadernos de Ciência \& Tecnologia, Brasília, v. 21, n. 2, p. 279-309, maio/ago. 2004.

Conforme demonstra a tabela 6 , o consumo médio de herbicidas entre os estados norte-americanos que utilizam o herbicida RR nos seus cultivos é $13 \%$ superior ao cultivo convencional. No estado de Iowa, um dos principais estados produtores de soja, o uso de herbicida (glifosato) é 30\% superior ao utilizado pela soja convencional. Os resultados da tabela 6 apresentam uma variância na utilização de herbicida muito grande. No estado de Michigan, por exemplo, o uso de herbicidas pela soja transgênica foi $30 \%$ inferior a sua variedade convencional. Por outro lado, no estado de Arkansas esse resultado foi o inverso, apresentando uma taxa de uso de herbicidas pela variedade transgênica de $63 \%$ superior à soja convencional. A explicação, segundo BENBROOK (2001), para estes resultados são as respostas diferenciadas em relação às mudanças ambientais que cada região apresenta (estresse hídrico, fixação de nitrogênio, solo, cultivo).

Além disso, a eficácia do uso do herbicida glifosato pode mudar ao longo do tempo em função da resistência das ervas daninhas. Quanto mais resistentes tornam-se as pragas e 
ervas daninhas, maior a quantidade necessária de aplicação do herbicida. Segundo Pelaez et al. (2004, apud: Benbrook 2001, Duffy 1999, Hartzler 1999 e Herbicide Resistance Action Committee 2001), “o uso de herbicidas em culturas de soja RR está aumentando gradualmente em função da variabilidade das ervas daninhas, crescimento tardio de algumas ervas daninhas e perda de susceptibilidade ao glifosato em algumas dessas espécies”.

\section{Produtividade}

A tabela 7 apresenta a evolução da produtividade média de soja nos EUA, no Brasil e na Argentina, no período de 1969 a 2003.

Tabela 7. Comparação de produtividade média da soja entre os principais países produtores

\begin{tabular}{ccccccc}
\hline \multirow{2}{*}{ Ano } & \multicolumn{5}{c}{ Produtividade (t/ha) } \\
\cline { 2 - 6 } & \multicolumn{2}{c}{ EUA } & \multicolumn{2}{c}{ Brasil } & Argentina \\
\hline $1969 / 71$ & & 1,83 & & 1,22 & 1,28 \\
$1989 / 91$ & & 2,26 & & 1,79 & 2,31 \\
$1993 / 94$ & & 2,19 & & & & \\
$1994 / 95$ & & 2,78 & & 2,16 & & 2,3 \\
$1995 / 96$ & & 2,38 & & 2,22 & & 2,19 \\
$1996 / 97$ & 100 & 2,53 & 100 & 2,2 & 100 & 2,08 \\
$1997 / 98$ & 103,6 & 2,62 & 105 & 2,31 & 87 & 1,81 \\
$1998 / 99$ & 103,6 & 2,62 & 113,6 & 2,5 & 134,6 & 2,8 \\
$1999 / 00$ & 97,2 & 2,46 & 110,4 & 2,43 & 117,8 & 2,45 \\
$2000 / 01$ & 101,2 & 2,56 & 114,1 & 2,51 & 118,7 & 2,47 \\
$2001 / 02$ & 105,1 & 2,66 & 127,3 & 2,8 & 128,4 & 2,67 \\
$2002 / 03$ & 100,4 & 2,54 & 120,9 & 2,66 & 126,4 & 2,63 \\
Evolução da produtividade & & $\mathbf{3 8 , 8 0}$ & & $\mathbf{1 1 8 , 0 3}$ & & $\mathbf{1 0 5 , 4 7}$ \\
\hline
\end{tabular}

Fonte: Pelaez et al., 2004 (Apud: Schenpf et al. 2001 e Usda 2003)

Observe que no período a produtividade média da soja brasileira (118\%) e Argentina $(105,5 \%)$, foram muito superiores ao verificado pela soja norte-americana, com crescimento de 38,8\%. A produtividade média da soja brasileira tem evoluído ano após ano, conseguindo ultrapassar a produtividade da soja Argentina na safra 2000/01, e a produtividade da soja norte-americana na safra 2001/02. Se atentarmos a mais um detalhe da tabela 7 , a partir da safra 1996/97, ano em que a difusão de OGMs nos EUA e Argentina tornam-se mais consistente, verificamos-se que os EUA apresentaram a mesma produtividade na safra 2002/03, enquanto que a Argentina - no mesmo período - alcançou ganhos de 26,4\%. Dois 
países que utilizam a mesma tecnologia de plantio (transgênica) apresentam resultados bem distintos.

Esses resultados revelam a dificuldade de se comparar os sistemas de produção de cada país, onde uma série de fatores - clima, métodos de cultivo, uso de herbicidas - pode influenciar no desempenho da produção (Pelaez, 2004 apud: Benbrook, 1999). Por outro lado, o Brasil que na época mantinha quase toda a sua produção de soja pelo método convencional alcançou uma produtividade de $21 \%$. Esse aumento decorreu em função de pesquisas realizadas pela Embrapa para a fixação do nitrogênio por meio da associação simbiótica com a bactéria Rbizobium (Pelaez et al. 2004. apud Döbereiner; Arruda, 1997; Brose et al., 1979; Vargas et al., 1982; Bohrer; Hungria, 1997). Esses dados revelam que, em termos de produtividade, a adoção de uma determinada tecnologia (convencional versus transgênica) ainda não representa uma superioridade perante a outra.

\section{Considerações finais}

As considerações finais que se podem emitir sobre a superioridade econômica - de custos e de produtividade - de uma tecnologia baseada em melhoramento genético, ainda são inconclusivas. As informações que são veiculadas, obedecendo a uma estratégia comercial das empresas, de que a tecnologia da soja transgênica é superior a tecnologia da soja convencional por apresentar um custo de produção inferior, um uso menor de herbicidas no meio ambiente e uma produtividade maior, não se verificou em dois dos três itens aqui analisados. Além do mais, as informações que existem ainda são incertas, incapazes de gerar laudos conclusivos sobre a superioridade de uma tecnologia perante a outra, pois se baseiam numa análise estática, sem uma série histórica capaz de identificar uma tendência consistente. Por exemplo, os custos de produção da soja transgênica e a utilização de herbicidas no cultivo de soja nos EUA e na Argentina são analisados apenas em um período. Apenas o item produtividade é capaz de mostrar uma tendência e mesmo assim, contraditória.

Em ambos os países que utilizam a técnica de plantio baseada na tecnologia transgênica, observam-se que a produtividade da soja dos EUA (índice na tabela 7) é praticamente a mesma no período 1996/2003. Enquanto que na Argentina, no mesmo período, houve um aumento de $26 \%$ de sua produtividade no cultivo de soja. Esses dados revelam as incertezas e contradições, em termos de produtividade, que a tecnologia transgênica apresenta. Por outro lado, o Brasil que mantinha quase toda a sua produção de soja convencional obteve no mesmo período uma produtividade de 20,9\%. 


\section{Referências bibliográficas}

ALBERGONI, L.; GUERRA, M.; PELAEZ, V. Soja transgênica versus soja convencional: uma análise comparativa de custos e benefícios. In: Cadernos de Ciências \& Tecnologia, Brasília, v. 21, n.2, p. 279-309, maio/ago. 2004.

GOLDIN, I.; REZENDE, G. A agricultura brasileira na década de 80: crescimento numa economia em crise. In: Série IPE A, n. 138, Rio de Janeiro, 1993.

GUERRA, M; NODARI, R. Plantas transgênicas e seus produtos: impactos, riscos e segurança alimentar (Biossegurança de plantas transgênicas). In: Revista de Nutrição, Campinas, n. 16(1), p. 105-116, jan./mar. 2003.

ISAAA. International Service for the Acquisition of Agri-biotech Applications. Sumário Executivo. JAMES, C. Global status of commercialized Bitech/GM crop: 2005. n. 34, 2005. 